Univerzitet umetnosti u Beogradu, Uneskova katedra za kulturnu politiku i menadžment, Beograd

UDK: $304.4(4)$

331.5.024.5:008(4)

\title{
POLITIKAZAPOŠLJAVANJA UOBLASTIKULTURE
}

Sažetak: Politika zapošljavanja u kulturi je po svojoj prirodi sastavni deo rešavanja statusa umetnika. Ona može biti kako stimulativni, tako i restriktivni instrument kulturnog razvoja neke zemlje. Cilj ovog rada jeste da, poredeći politiku zapošljavanja u oblasti kulture u Velikoj Britaniji, Finskoj, Rusiji i Srbiji, ukaže na povezanost kulturnog razvoja i politike zapošljavanja u kulturi, te da na osnovu primera dobre prakse kreira listu opštih predloga i preporuka za sve četiri zemlje, kao i listu specifičnih preporuka za Srbiju. Osnovna teza od koje polazi rad jeste da suviše afirmativna politika zapošljavanja, koja teži ka tome da obezbedi stalan posao velikom broju radnika u kulturi, može voditi ka stagnaciji cele oblasti, isto koliko veoma restriktivne i generalizovane mere za zapošljavanje i prepuštenost slobodnom tržištu mogu povećati nezaposlenost. Stoga su $i$ preporuke na kraju rada usmerene na izbalansirano korišćenje stimulativnih $i$ restriktivnih instrumenata kulturne politike, te prilagođene specifičnim problemima i uređenju svake od pomenutih zemalja.

Ključne reči: zapošljavanje, status umetnika, slobodni umetnici, socijalna zaštita

\section{Uvod}

Pre dvadeset godina, na 21. generalnoj konferenciji UNESCO-a u Beogradu, 1980. godine, zemlje članice iz svih krajeva sveta su raspravljale o mogućim načinima zaštite socijalnih, ekonomskih i profesionalnih prava umetnika. Tada je sačinjena Lista preporuka u vezi sa statusom umetnika, koja (između ostalog) kaže da ,uslovi za rad i zapošljavanje umetnika treba da budu takvi da daju priliku svim umetnicima koji to žele da se potpuno 
posvete svojim umetničkim aktivnostima."1 U stvarnosti, međutim, različite zemlje su sa različitom ozbiljnošću preduzele predložene mere, što je rezultiralo mnogobrojnim i kvalitativno različitim metodama regulacije umetničkog statusa. ${ }^{2}$

Politika zapošljavanja u kulturi je po svojoj prirodi sastavni deo rešavanja statusa umetnika. Ona može biti kako stimulativni, tako i restriktivni instrument kulturnog razvoja neke zemlje. Politika zapošljavanja podrazumeva integraciju nekoliko oblasti politike, pre svega ekonomije, socijalne i zdravstvene zaštite, rada. To je čini izuzetno kompleksnom i zanimljivom temom za diskusiju.

Cilj ovog rada jeste da uporedi politiku zapošljavanja u oblasti kulture dve zemlje članice Evropske unije i dve zemlje koje to nisu, te da kreira listu predloga i preporuka za jednu od njih (u ovom slučaju Srbiju) na osnovu uočenih problema i primera dobre prakse. Zemlje čije ćemo politike ovom prilikom analizirati jesu Velika Britanija, Finska, Rusija i Srbija, a izabrane su po principu različitosti geografske pozicije, političkog uređenja i statusa u odnosu na EU (novija/starija članica, kandidat/nije kandidat za priključenje).

Zbog jasnoće i ekonomičnosti rada, nećemo ulaziti u dublju analizu politike zapošljavanja u oblasti kulture svake zemlje. Izložićemo i analizirati samo osnovne principe, fokusirajući se na odnos između usmerenja kulturne politike (kratkoročnih i dugoročnih ciljeva) i njenih instrumenata (tj. programa i akcija koji se primenjuju). Međutim, dotaći ćemo se i povezanih tema kao što su izvori finansiranja, poreska politika, obrazovanje itd., koje takođe utiču na status umetnika (i drugih radnika u kulturi), a naročito na njihove uslove zapošljavanja. Konačno, stavljajući akcenat na politiku zapošljavanja u oblasti kulture u Srbiji, ovaj rad će ponuditi predloge za najbolji pravac delovanja u svakoj zemlji, na osnovu specifičnih potreba njihovih umetnika i radnika u kulturi i primera dobre prakse u drugim evropskim zemljama.

1 UNESCO Recommendation concerning the Status of the Artists (Belgrade 1980), 05. januar 2010, http://portal.unesco.org/en/

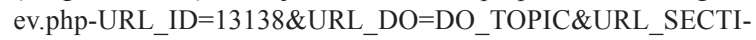
$\mathrm{ON}=201 . \mathrm{html}$

2 Više o rešavanju statusa umetnika u različitim evropskim zemljama u dokumentu organizacije ERICarts Institute, The Status of Artists in Europe, European Parliament 2006. 


\section{Zapošljavanje u kulturi-opis trenutne situacije}

Kultura je u Velikoj Britaniji prepoznata kao fundamentalno pravo svakog pojedinca i kao ključni faktor unapređenja kvaliteta svakodnevnog života. ${ }^{3}$ Iz tog razloga, primarni cilj britanske kulturne politike jeste da se pobrine da je nacionalna kulturna ponuda istinski kvalitetna, da ima potencijal da pozitivno utiče na živote ljudi i da je dostupna širokoj publici. Ovakva orijentacija se takođe ogleda i u metodama finansiranja kulture, koje su najčešće u formi dotacija, ${ }^{4}$ podrške projektima kroz fondacije ili u formi nagradnih sponzorstava. Stoga podrška umetnicima i radnicima u kulturi od strane Velike Britanije kao države zavisi od umetničkog dostignuća, ispunjenja određenih ciljeva i inovativnosti umetničkog rada, a ne od socijalnog ili radnog (zaposlen/nezaposlen) statusa umetnika. Kao takvi, metodi podrške umetnicima u Britaniji se u mnogome razlikuju od metoda socijalne zaštite u nordijskim zemljama.

Međutim, u Britaniji ne postoji generalni zakonodavni okvir u kulturi niti postoje posebni zakoni koji se odnose na zapošljavanje umetnika. Rad umetnika je regulisan opštim zakonom o radu. Isto tako, ne postoji ni poseban zakon o socijalnoj zaštiti kojim se uređuje status samozaposlenih umetnika.

Ipak, nakon 1998. godine, kada je vlada donela izmene pravila o ,zabavljačima“, slobodni umetnici su ostvarili pravo na naknadu za traženje posla ${ }^{5}$ dok se „odmaraju“, kao i ostali radnici van kulturnog sektora. Naknada za traženje posla je deo britanskog sistema socijalne zaštite kojom je omogućeno da nezaposleni ljudi dobijaju osnovnu finansijsku pomoć u trajanju od 182 dana dok efektivno tragaju za drugim poslom. Kao takva, ova naknada je od krucijalne važnosti za kulturni sektor u kojem je učestalost sezonskih poslova, kratkoročnih ugovora (po projek-

tu) i privremenog zapošljavanja veoma velika.

Uprkos nedostatku specifičnih mera za zapošljavanje radnika u kulturi, preduzet je velik broj akcija koje se

3 United Kingdom Cultural Policy Profile, Compendium: Cultural Policies and Trends in Europe, 28. novembar 2008, 05. januar 2010, http://www.culturalpolicies.net/web/unitedkingdom.php?aid=1

4 Ove se dotacije distribuiraju pomoću velikog broja nezavisnih javnih tela (eng. Non-Departmental Public Bodies), kao što su Umetnički saveti. Ovaj princip, popularno nazvan principom ,na dužini ruke“, oslikava britansku politiku pružanja podjednake šanse građanima iz svih regiona da uživaju u kulturnim dobrima ili imaju koristi od kulturnih fondova.

$5 \quad$ Eng. job seekers allowance. 
prevashodno odnose na druge oblasti kulturne politike, ali kojima se značajno utiče na uslove zapošljavanja $u$ oblasti kulture:

Prvo, tu su poreski propisi - sve donacije i nagrade za umetnike su oporezive. Međutim, određene grupe umetnika (pisci, kompozitori, dramaturzi i drugi) imaju mogućnost da, u dogovoru sa upravom poreskih prihoda, razvuku plaćanje svojih taksi na nekoliko godina, ali samo ako mogu da dokažu da njihovi prihodi značajno variraju kao posledica toga što pojedinih godina više vremena troše na kreativni proces, kada su im i prihodi niži od uobičajenih. Umetnici takođe mogu dobiti poreske olakšice na troškove profesionalnog usavršavanja.

Drugo, razvijen je veliki broj edukativnih programa ( $\mathrm{Cul}$ tural Leadership Programme, Clore Leadership Progra$m m e$, itd.) čiji je za cilj trening nove generacije rukovodilaca u oblasti kulture i njihovo ovladavanje specifičnim veštinama i znanjima koja se trenutno traže na tržištu rada u kulturi. Postoje takođe i organizacije (kao što je, na primer, Creative and Cultural Skills) koje komuniciraju sa poslodavcima velikih i malih preduzeća u kulturi kako bi ih uverili da njihovi budući zaposleni zaista imaju pristup kvalitetnom obrazovanju. Ove organizacije rade i na tome da povećaju stručnu relevantnost kvalifikacija koje su u ponudi i informišu studente o izboru kurseva i mogućim pravcima razvoja karijere. Škotski programi za stažiste i stipendiste ${ }^{6}$ obezbeđuju mesta za novokvalifikovane stručnjake konzervacije, sa ciljem da se unaprede veštine i sposobnosti zaštite i konzervacije u Škotskoj.

Treće, preduzet je veliki broj mera za unapređenje daljeg razvoja kreativnih industrija, koje su još u 2001. godini obezbeđivale 1.3 miliona radnih mesta i ostvarile $£ 112.5$ biliona prihoda. Dok su se neke mere odnosile na podršku preduzećima, izvoz i finansiranje, druge su bile više usmerene na pitanja vezana za zapošljavanje, kao što je razvoj preduzetništva, poslovnih veština i kreativnog partnerstva. ${ }^{7}$

Konačno, postoje i posebni programi koji se direktno bave pitanjima zapošljavanja umetnika, kao što je Novi posao za muzičare. ${ }^{8}$ Ovaj program pomaže nezaposlenim muzičarima (uključujući instrumentaliste, vokalne umetnike, kompozitore, pisce pesama i di-džejeve) da brže napreduju u muzičkoj industriji, bilo kao umetnici pod ugovorom ili kao samozaposleni, obezbeđujući ih neophodnim veštinama, kontaktima i savetima.

6 Eng. Interns and Fellows Programmes.

7 Creative Industries, 5. april 2010., http://www.culture.gov.uk/ what_we_do/Creative_industries/

8 Eng. The New Deal for Musicians. 
Vredno je napomenuti i da mnogobrojni Umetnički saveti deluju u saradnji s različitim umetničkim udruženjima koja pomažu umetnike tako što otkupljuju njihove radove, daju im informacije o mogućnostima zaposlenja i stručnog usavršavanja, zalažu se za njihova prava i obezbeđuju profesionalne, pravne, zdravstvene i socijalne beneficije za svoje članove. Jedno takvo udruženje je Pravednost, ${ }^{9}$ čiji je osnovni cilj da pregovara o minimalnim uslovima zapošljavanja svojih članova u čitavoj industriji zabave i da osigura da su ti uslovi usklađeni sa socijalnim i ekonomskim promenama. ${ }^{10}$

Po pitanju zapošljavanja u Finskoj, još od proglašenja nezavisnosti Finske, 1918. godine, promocija umetničke kreativnosti je bila i ostala jedan od osnovnih ciljeva kulturne politike ove zemlje. To se ogledalo u kontinuiranom razvoju sistema dotacija i penzija, pomoću kojih je „država blagostanja“ težila da zbrine svoje umetnike.

S druge strane, ideje da kultura može doprineti regionalnom razvoju, ekonomskom porastu i povećanju izvoza i zaposlenosti takođe su postale prepoznate u Finskoj. Iz ovog razloga, „obezbeđivanje sredstava za poboljšanje kulturnih i ekonomskih kompetitivnih kapaciteta u finskom društvu“ i ,poboljšanje efektivnosti kulturnog sektora" i jesu navedeni kao dva važna cilja (uz nekoliko drugih) u strategiji Ministarstva obrazovanja i kulture do 2015. godine. ${ }^{11}$ Zapošljavanje u oblasti kulture nikada nije bilo cilj finske kulturne politike; izvestan broj mera koje ga direktno ili indirektno podržavaju je, ipak, razvijen.

Akt o radnim ugovorima i Akt o državnim službenicima su dva osnovna pravna instrumenta koji regulišu upotrebu finske radne snage. Svi radnici u kulturi i profesionalci koji su zaposleni u javnim kulturnim institucijama, kao i oni koji su stalno zaposleni u privatnim preduzećima u oblasti kulturnih industrija, potpadaju pod ove akte. Međutim, ovi akti ne važe za samozaposlene i honorarne radnike u kulturi, kao ni opšte socijalno osiguranje i sistem kolektivnog pregovaranja. U slučaju nezaposlenosti, oni mogu dobiti olakšice za nezaposlene samo ako izvade privatno osiguranje. Ni poslednji finski Nacionalni plan za zapošljavanje, iz 2004. godine, ne obraća posebnu pažnju na tržište rada u kulturi.

Opšti Zakon o penzijama i Akt o penzijama umetnika $i$ posebnim grupama privremenih radnika regulišu situa-

$9 \quad$ Eng. EQUITY

10 What is Equity, 5. april 2010., http://www.equity.org.uk/AboutUs/ WhatIsEquity.aspx

11 Finland Cultural Policy Profile, Compendium: Cultural Policies and Trends in Europe, 30. novembar 2008., 05. januar 2010., http:// www.culturalpolicies.net/web/finland.php?aid=33 
ciju slobodnih umetnika i profesionalaca koji rade u prostorijama poslodavaca. Stariji umetnici koji su još uvek profesionalno aktivni podržani su i posebnim sistemom umetničkih penzija, kojim zajednički upravljaju Ministarstvo obrazovanja i kulture (MEA) i Ministarstvo finansija. Ovim sistemom su im omogućene redovne fiksne mesečne isplate. Međutim, pozicija onih umetnika koji su dugo bili finansirani neoporezivim dotacijama je i dalje slaba, jer ove dotacije nisu uračunate u njihove penzije.

Dalje, umetnici su direktno podržani i raspodelom dotacija (grantova), koje imaju svoju pravnu osnovu u Aktu o dotacijama za umetnike i profesore umetnosti. Na osnovu ovog akta, brojni oblici direktne podrške su pruženi: umetničke dugoročne dotacije (od pola godine do pet godina - smatraju se olakšicom za nezaposlene); dotacije za projekte; penzije za izuzetne umetnike; dotacije dramskim piscima; naknade za vizuelne umetnike; naknade za pisce, muzičare i kompozitore za upotrebu njihovih dela u bibliotekama.

Konačno, samozaposleni umetnici imaju pravo na odbitak poreza na dohodak i pravo da im se kao osnovica za penziju uzima prosek svih honorara. Sindikati i udruženja umetnika deluju kao veoma jaka tela za kolektivno pregovaranje.

Razmatrajući zapošljavanje u Rusiji, uviđamo da kulturna politika Ruske federacije još od 2000. godine prolazi kroz velike promene: od finansijske podrške državnih kulturnih institucija kao prioriteta samog po sebi ka raznovrsnijim i tržišno orijentisanim principima upravljanja kulturom. ${ }^{12}$ Prema Konceptu dugoročnog društvenog i ekonomskog razvoja Ruske federacije od 2008. do 2020. godine, predstavljenom od strane Ministarstva ekonomskog razvoja, razvoj i realizovanje ličnih i društvenih kulturnih potencijala jesu osnovni cilj kulturne politike u okviru sveukupnog prelaza na inovativnu ekonomiju.

Kulturni odnosi su regulisani velikim brojem opštih zakona i propisa. Međutim, na novoj verziji Zakona o kulturi se radi još od 2000. godine. Zakon o kreativnim radnicima u književnosti i umetnosti i o njihovim kreativnim sindikatima je dva puta prolazio kroz parlament i dva puta je bio odbijen od strane predsednika, jer je, smatra se, predviđao privilegije i izuzeća od važećih zakona.

Zapošljavanje je generalno regulisano Pravilnikom o ra$d u$. Ovaj pravilnik propisuje standarde minimalnih zarada u javnom sektoru, ali ne sadrži nikakve regulative

12 Russia Cultural Policy Profile, Compendium: Cultural Policies and Trends in Europe, 01. septembar 2009, 05. januar 2010, http:// www.culturalpolicies.net/web/russia.php 
vezane za honorarne radnike i samozaposlene. Međutim, zbog dominantne državne kulturne infrastrukture, $80 \%$ umetnika i radnika u kulturi je stalno zaposleno u državnim ustanovama ili su članovi kreativnih sindikata (čime dobijaju isti status kao zaposleni).

Ipak, zaposleni u državnim ustanovama kulture primaju najniže zarade u odnosu na druge radnike u javnom sektoru. Situacija je još dramatičnija u nerazvijenim regionima i ruralnim oblastima, otežana činjenicom da su mnogi radnici stari i školovani u starom socijalističkom sistemu „države blagostanja“. To je dovelo i do nedostatka radne snage, manjka mladih koji ulaze u oblast kulture i do „odliva mozgova“. Stoga je 2008. godine i uveden poseban način obračuna zarade za zaposlene u kulturi, kako bi se plate povećale za $30 \%$.

Kako je i dalje većina umetnika zaposlena u državnim institucijama, za njih nisu razvijene posebne mere socijalnog osiguranja. Honorarci i samozaposleni umetnici nisu socijalno zaštićeni ni na koji način. Regionalne vlasti imaju pravo da organizuju sopstvene službe za zapošljavanje i razviju posebne fondove za podršku nezaposlenima.

S druge strane, Ministarstvo kulture obezbeđuje državne fondove za kreativne sindikate, koji potom vrše raspodelu novca svojim članovima. U 2008. godini, Ministarstvo je obezbedilo 30,000.000 rubalja pomoći za 70.000 članova kreativnih sindikata.

Umetnici su podržani i putem redovnih državnih narudžbina i otkupa umetničkih dela, kao i sistemom dotacija i nagrada, koji se ubrzano razvija od 2000. godine, kako na federalnom tako i na regionalnim nivoima. Godine 2007. je uspostavljena Nagrada Kandinski za najboljeg savremenog ruskog umetnika (ekvivalent Tarnerovoj nagradi ili Nagradi Marsel Dišan), sa nagradnim fondom od 55,000 evra i međunarodnim žirijem. Ipak, većina nagrada se dodeljuje za prethodna dostignuća; nagrade kojima se podstiču kreativni procesi još uvek ne postoje.

Dodatna socijalna pomoć i privilegije za umetnike su obezbeđeni putem počasnih diploma, tradicijom koja potiče još iz sovjetskog perioda. Umetnici u penziji i invalidi mogu imati posebne koristi od ovih diploma, dok Odbor za kulturu lobira u državnoj Dumi za povećanje njihovih penzija. Istaknuti umetnici u godinama takođe imaju mogućnost da dobiju doživotnu predsedničku dotaciju.

Po pitanju zapošljavanja u kulturi, i Srbija ima niz specifičnosti. Kako zbog tranzicije, tako i zbog mnogobrojnih promena u strukturi vlade, prioriteti kulturne politike Re- 
publike Srbije su se menjali nekoliko puta od 2001. godine. Ipak, u 2008. godini, ,transformacija, racionalizacija, koncentracija i inovacija" prepoznate su kao ključne reči tekuće kulturne politike. ${ }^{13}$ Među prioritetima kulturne politike našle su se i reorganizacija javnih ustanova kulture i razvoj preduzetničkog duha u kulturi, drugim rečima - rešenje pitanja zapošljavanja u kulturi.

Međutim, reorganizacija se u stvarnosti odvija izuzetno polako, s obzirom da ne postoje specijalne radne grupe koje bi ispitale mogućnosti za razvoj preduzetništva u oblasti kulture. Relativno velik broj inicijativa za samozapošljavanje (nove medijske kuće, pozorišne trupe, itd.), kao i značajan „odliv mozgova“ učinili su da izgleda kao da tržište rada u kulturi još uvek nije tako velik problem. To će se verovatno uskoro promeniti, jer se velik broj mladih umetnika sa privatnih univerziteta pojavljuje na tržištu.

Novi Zakon o radu ${ }^{14}$ i Zakon o državnoj upravi ${ }^{15}$ (2005) su doneli mnoge promene, a među najvažnijima je svakako ukidanje dvostrukog zapošljavanja u javnom sektoru. Ovom zabranom onemogućeno je da umetnici koji su stalno zaposleni na umetničkim univerzitetima istovremeno budu zaposleni i u javnim pozorištima (na primer).

Stupanjem na snagu novog Zakona o kulturi, ${ }^{16}$ u martu 2010. godine, dolazi do novih promena. Ovaj zakon u osnovnim crtama nagoveštava rekonstrukciju kulturnog sistema i daje naglašenu podršku profesionalnom usavršavanju. Najveća promena je, međutim, uvođenje javnog konkursa za izbor direktora javnih ustanova kulture, koji će ubuduće biti postavljani na period od četiri godine i čiji će strateški planovi biti evaluirani. Zakon takođe utiče i na radnike u kulturi, koji će ubuduće moći da se zaposle u javnim institucijama kulture na period do tri godine, uz mogućnost produženja ugovora. Osobe sa preko 20 (za muškarce), odnosno 17.5 (za žene) godina radnog staža moći će da dobiju status stalno zaposlenih lica.

Došlo je i do promene u statusu profesionalnih umetničkih udruženja, koja su sada mnogo nezavisnija nego ranije (dok su važila za državne sindikate). Zakon o udruženjima (2009), koji je uneo ove novine, imao je za cilj da aktivira udruženja da organizuju za svoje članove radionice profesionalnog usavršavanja i edukativne seminare,

13 Serbia Cultural Policy Profile, Compendium: Cultural Policies and Trends in Europe, 29. novembar 2009., 5. januar 2010., http:// www.culturalpolicies.net/web/serbia.php

14 Zakon o radu, Službeni glasnik R. Srbije, br. 24/ 05 i 61/05.

15 Zakon o državnoj upravi, Službeni glasnik R. Srbije, br. 79/2005 i 101/2007.

16 Zakon o kulturi, Službeni glasnik R. Srbije, br. 72/2009. 
čime bi povećale sopstvene prihode i pomogle otvaranje novih radnih mesta. ${ }^{17}$ Ipak, ove su promene prouzrokovale veliko nezadovoljstvo među udruženjima umetnika,

koja su se osetila odbačenim od strane države.

Status samozaposlenih umetnika još uvek mora da se redefiniše, što će biti ostvareno usvajanjem posebnih podzakona u okviru novog Zakona o kulturi. Od 1993. godine, njihov je status bio regulisan Zakonom o samostalnom obavljanju umetničke ili druge delatnosti u oblasti kulture, na osnovu kojeg su imali pravo na zdravstveno, penziono i invalidsko osiguranje, plaćeno od strane opštine u kojoj su prijavljeni. Samostalni umetnici su imali pravo da traže odbijanje između $40 \%$ i $65 \%$ poreza na lični dohodak za troškove koji se odnose na njihov rad (bez priložene dokumentacije).

Stvaralaštvo se takođe podržava i putem javnih konkursa za projekte u kulturi. Za kulturu je izdvojeno u ovu svrhu $13 \%$ iz državnog budžeta. Međutim, s obzirom na to da i ustanove kulture imaju pravo da konkurišu za ova sredstva, procenat koji se dodeljuje samostalnim umetnicima je izuzetno mali (približno $10 \%$ od onih $13 \%$ ). Mere za podsticanje samostalnih umetnika na stvaralaštvo (da napišu knjigu, komponuju muzičko delo, itd.) još uvek ne postoje. ${ }^{18}$

Ministarstvo kulture je u 2007. godini usvojilo novu Uredbu o specijalnom priznanju za vrhunski doprinos nacionalnoj kulturi odnosno kulturi nacionalnih manjina. Od tada se veliki broj dotacija (u formi doživotnih mesečnih isplata), popularno nazvanih nacionalne umetničke penzije, dodeljuje istaknutim starijim umetnicima.

Na kraju, u Srbiji i dalje nedostaje sistematska podrška za razvoj kulturnih industrija, uprkos tome što u ovoj oblasti deluje 1,316 aktivnih preduzeća i radi 21,397 radnika. Zapošljavanje u kulturnim industrijama je veoma specifično, a karakterišu ga velika fleksibilnost i mobilnost poslova, samostalni ugovori, samozapošljavanje, honorarni poslovi i drugo. 


\section{Osnovni problemi politike zapošljavanja u kulturi}

Kao što smo već rekli, kulturna politika Velike Britanije se umnogome razlikuje od sistema socijalnog staranja nordijskih zemalja. Tržište rada u kulturi je mahom prepušteno silama slobodnog tržišta i država retko interveniše po pitanju specifičnih uslova zapošljavanja u kulturi. Britanski kreatori kulturne politike imaju moto: „Ulaganjem u izvrsnost podstičemo zapošljavanje.“ Oni se stoga i usredsređuju na edukaciju mladih profesionalaca $\mathrm{i}$ mogućnosti doživotnog usavršavanja, stimulišući preduzetništvo i otvarajući različite mogućnosti za finansiranje inovativnih projekata (dotacije, konkursi). Ovakav proaktivan pristup se poklapa sa opštim ciljevima britanske kulturne politike i može biti pozitivno ocenjen.

Međutim, umetnici i kulturni radnici se susreću sa nekoliko problema po pitanju zapošljavanja:

1. Nezaposleni umetnici imaju prava na naknadu za traženje posla, kao i svi ostali građani. Međutim, ovom naknadom se pretpostavlja da umetnici aktivno traže posao koji je dostupan na tržištu rada. Odlike umetničkog posla nisu ovom prilikom uzete u obzir, naročito u slučaju pisaca ili likovnih umetnika, na primer, koji ponekad provode mnogo vremena razvijajući svoje ideje (dakle, radeći), a tretiraju se kao da traže posao.

2. Ne postoji zakon o samozaposlenim umetnicima, niti postoje bilo kakve mere socijalnog osiguranja (kao što su dodaci na penziju ili pomoć za nezaposlene) za samozaposlene radnike u oblasti kulture. S druge strane, 39\% radnika koji rade svoj glavni posao u kulturi je samozaposleno, u poređenju sa $12 \%$ samozaposlenih radnika van oblasti kulture. Primećena je i tendencija kontinuiranog porasta samozapošljava-

$$
\text { nja. }{ }^{19}
$$

3. Zaposleni u kulturi obično zarađuju manje od drugih profesija koje pripadaju istoj grupi prema Standardu za klasifikaciju profesija iz 1990. godine. Nikakve mere po ovom pitanju još uvek nisu preduzete.

Generalno, u Velikoj Britaniji postoje veoma razvijene opšte mere za zapošljavanje i socijalno osiguranje, ali nisu uzete u obzir specifične potrebe samozaposlenih $\mathrm{u}$ oblasti kulture. 
Ni u Finskoj pitanje zapošljavanja u kulturi nikada nije bilo prioritet samo po sebi. Ipak, razvijen je veliki broj programa kojima se štiti status umetnika i ,povećava kulturna i ekonomska kompetitivnost finskog društva“: odbijanje poreza na lični dohodak za samozaposlene umetnike, podrška nezaposlenima, dodatni penzioni fond (dotacije za starije umetnike), kompenzacije za pisce, kompozitore i likovne umetnike, dotacije za projekte i individualne umetnike, itd. Generalno govoreći, finsku kulturnu politiku odlikuje veoma proaktivan pristup. Ipak, postoji nekoliko problema koji tek treba da budu regulisani:

1. Nacionalni plan zapošljavanja (2004) nije uzeo u obzir specifičnosti tržišta rada u kulturi, što može ostaviti dugoročne negativne posledice. Ovo može biti i indikator nedovoljne saradnje između Ministarstva ekonomije i Ministarstva kulture, koja je neophodna po tako kompleksnim pitanjima kao što je zapošljavanje.

2. Umetnici često imaju problema sa dokazivanjem statusa nezaposlenog lica i ostvarivanjem prava na beneficije i osiguranje u slučaju nezaposlenosti. Minimalno pokriće je u mnogim slučajevima bilo nedovoljno i zahtevalo je od umetnika ili da izvade dodatno privatno osiguranje ili da steknu status plaćenog radnika.

3. Samozaposleni umetnici i preduzetnici čine samo 19\% ukupne radne snage u kulturi, u poređenju sa evropskim prosekom od 29\%. Oklevanje umetnika sa osnuju sopstvena preduzeća može biti posledica nedovoljne promocije preduzetništva i nedostatka stimulativnih zakona.

4. Broj školovanih mladih umetnika i profesionalaca u kulturi koji se pojavljuju na tržištu rada je sve veći.

Uprkos ovim primedbama, Finska ima veoma dobro razvijene instrumente u oblasti zapošljavanja u kulturi i konstantno se traga za novim rešenjima kako bi se popravili uslovi zapošljavanja u ovoj oblasti. Ministarstvo kulture veoma brzo reaguje i o gore pomenutim problemima se već uveliko pregovara. Generalno, ciljevi finske kulturne politike se poklapaju sa merama koje su preduzete.

Situacija je, pak, znatno drugačija u Rusiji. Svest o tome da oblast kulture mora postati više preduzetnička i tržišno orijentisana, te nezavisna od državnog budžeta, raste u Rusiji. Ipak, u stvarnosti i dalje dominira stari sovjetski model kulturnih ustanova koje zavise od državnog budžeta. Na ovaj se nadovezuje još nekoliko problema:

1. Stalno zaposleni radnici dominiraju u oblasti kulture - broj stalno zaposlenih u državnim ustanovama 
kulture je dosegao 815000 u 2007. godini. Opasnosti ovakvog sistema još uvek nisu prepoznate: on blokira umetnički razvoj, vezuje umetnike i čini da su ustanove indiferentne prema tržišnoj potražnji i nalaženju dodatnih izvora prihoda.

2. U poređenju sa drugim radnicima u javnom sektoru, plate radnika u javnim ustanovama kulture su najniže. Primetan je nedostatak kvalifikovanih radnika koji poznaju nove tehnologije i snalaze se u novoj ekonomskoj situaciji. Povećanje zarada bi bilo samo kratkoročno rešenje. Očigledan je i nedostatak pravnih (poreskih) regulativa kojima bi se stimulisalo preduzetništvo i partnerstvo između javnog i privatnog sektora, kao i nedostatak edukativnih programa za menadžere $\mathrm{i}$ administratore $\mathrm{u}$ kulturi.

3. Situacija u svakom regionu se veoma razlikuje, što dovodi do nedostatka kvalifikovanih radnika u manje razvijenim regionima. Harmonizacija federalnog i regionalnih zakona na jednoj i finansijska i pravna sloboda opština na drugoj strani, ostaju gorući problem. Kreiranje i implementacija strategije regionalnog razvoja čini se kao neophodan korak.

4. Status slobodnih i samozaposlenih umetnika nije zakonski regulisan, pa za njih ne postoje dodatne mere socijalnog osiguranja. Specifičnosti njihovog statusa i profesionalnih uslova nisu prepoznate. Podrška koju dobijaju preko umetničkih udruženja (unija, sindikata) nije dovoljna da pokrije osnovne životne troškove.

5. Iako država dodeljuje umetnicima velik broj dotacija, one se uglavnom dodeljuju ex post, kao priznanje za već ostvarena dostignuća. Ne postoje mere kojima se stimuliše individualno stvaralaštvo i produkcija, kao što su konkursi za projekte, javni pozivi za pisce, slikare, kompozitore, itd.

Pored ovih problema, Rusija se i dalje suočava sa problemom korupcije i istrajnošću prevaziđenog shvatanja uloge kulture u društvu, koji značajno usporavaju implementaciju novog modela kulturne politike. Zbog toga se i instrumenti kulturne politike Rusije ne poklapaju sa njenim ciljevima na zadovoljavajućem nivou.

Konačno, analizirajući situaciju u Srbiji, uviđamo da se u poslednjih desetak godina Srbija suočava sa procesom redefinisanja kulturnih vrednosti. Mnoga problematična pitanja, kao što je prevelik broj stalno zaposlenih u ustanovama kulture, su prepoznata od strane kreatora kulturne politike. Promene koje su zavedene novim Zakonom o kulturi, naišle su na velik otpor među umetnicima, zbog nejasnih perspektiva koje nudi novi model zapošljava- 
nja. Preovlađuje mišljenje da tržišno orijentisana kulturna produkcija ne može da pruži dovoljno mogućnosti za sve umetnike, jer neophodne pravne regulative još uvek nisu dovoljno razvijene. Sledeći problemi se i dalje čine akutnim: ${ }^{20}$

1. Privatizacija, ekonomija slobodnog tržišta i smanjenje podrške iz državnog budžeta mogu prouzrokovati nezaposlenost, ukoliko se ne razviju dodatne mere (kao što je socijalno osiguranje, dokvalifikacija i profesionalno usavršavanje, itd.) kojima bi se zaštitio status slobodnih umetnika i koje bi ih snabdele neophodnim znanjima i veštinama za opstanak u uslovima slobodnog tržišta.

2. Nedostaje dodatna pomoć slobodnim umetnicima u slučaju nezaposlenosti. Potrebna je i veća kontrola da li opštine redovno plaćaju socijalno osiguranje za slobodne umetnike.

3. Distribucijom subvencija se i dalje više favorizuju institucije nego individualni umetnici, što znači da umetnički kvalitet i rezultati i dalje nisu osnovni kriterijum za dobijanje finansijske podrške od strane javnih vlasti (na svim nivoima).

4. Većina dotacija je namenjena prezentaciji gotovih dela. Nedostaje više podsticajnih mera od strane javnih vlasti ili ustanova kulture za pisanje knjige, razvoj scenarija, stvaranje dela iz oblasti vizuelnih umetnosti, itd.

5. Specifični uslovi zapošljavanja u kulturnim i kreativnim industrijama i u kulturnom turizmu nisu prepoznati, kao ni njihov ekonomski doprinos i potencijal za stvaranje novih radnih mesta. ${ }^{21}$ To se oslikava u slaboj finansijskoj podršci za njihov razvoj i nedostatku mera kojima bi se regulisao status radnika u ovim međuresornim oblastima.

6. Udruženja umetnika i dalje ne funkcionišu kao sindikati. U sistemu ne postoje privatni umetnički agenti, kao ni jedinstvena baza podataka pomoću koje bi, na primer, pozorišni umetnici mogli da se informišu o

20 Indikativno je to što je većina navedenih problema primećena još 2003. godine u nacionalnom izveštaju za projekat Saveta Evrope pod nazivom Mozaik (eng. MOSAIC: European Programme of National Cultural Policy Reviews). Dragičević Šešić M., Cultural Policy in Serbia: National Report. Council of Europe 2003.

21 O ekonomskom doprinosu međuresornih oblasti poput kulturnih i kreativnih industrija i kulturnog turizma, kao i o mogućnostima zapošljavanja u ovim oblastima, videti više u Đukić V., Država $i$ kultura, Institut za film, pozorište, radio i televiziju, Fakultet dramskih umetnosti Beograd 2010, str. 336-343 
novim mogućnostima zaposlenja, audicijama, kastinzima i slično.

7. Obrazovanje velikog broja mladih profesionalaca $u$ sektoru kulture nije prilagođeno novim potrebama tržišta rada u kulturi.

Da zaključimo, Srbija još uvek treba da razvije mnoge instrumente i strategije kulturne politike na svom putu ka demokratskom društvu sa energičnom i bogatom kulturnom ponudom. To se pre svega odnosi na strategiju diversifikacije ljudskih resursa, kojom bi se obogatila i kvalitativno unapredila kadrovska struktura u resoru kulture i srodnim međuresornim oblastima (kreativnim i kulturnim industrijama, kulturnom turizmu, art terapiji, itd.)

\section{Analiza mera za zapošljavanje u kulturi}

Poređenjem navedenih informacija, možemo da zaključimo sledeće:

- Politika zapošljavanja u oblasti kulture je mnogo razvijenija u zemljama članicama Evropske unije nego u onima koje to nisu. Velika Britanija i Finska su razvile čitav niz mera i instrumenata kojima podstiču kulturnu produkciju i zapošljavanje. Rusija i Srbija se i dalje bore sa tranzicionim okolnostima, koje usporavaju restrukturiranje čitave oblasti.

- Radna snaga u kulturi je mnogo više preduzetnički orijentisana u dve zemlje Evropske unije nego u druge dve. Po ovom pitanju Velika Britanija je apsolutni lider, jer je čitav kulturni sistem vrlo tržišno orijentisan i svi akteri u ovoj oblasti su naviknuti na traženje/stvaranje dodatnih izvora prihoda, a ne na isključivo oslanjanje na državne dotacije. ${ }^{22} \mathrm{Sa}-$ svim suprotno, ruski kulturni sistem je najpasivniji i koncentrisan u ustanovama koje zavise od države, delimično i zbog nedostatka pravnih mera kojima se podstiču javno-privatna partnerstva u kulturi.

- Zemlje članice Evropske unije ulažu mnogo više u kreativne procese i kulturnu produkciju nego što to čine Rusija i Srbija, koje su više usredsređene na nagrađivanje već gotovih dela.

- Status samozaposlenih i slobodnih umetnika se razlikuje od zemlje do zemlje, mada u svakoj još uvek treba da bude regulisan. Generalno, svakoj zemlji nedostaje bolji uvid u specifične uslove zapošljava-

22 Dufton, B. Cultural Policy in Serbia and Montenegro: Part I: Republic of Serbia Experts' Report. Council of Europe 2003, str. 31. 
nja u određenim umetničkim profesijama. Srbija je jedina zemlja koja ima poseban zakon o samostalnim umetnicima, dok im ostale tri zemlje ne daju mnogo zakonskih ,privilegija“. ${ }^{23}$

\section{Zaključak i preporuke u vezi sa zapošljavanjem u oblasti kulture}

Kulturna politika svake zemlje mora jednim svojim delom biti usredsređena na uočavanje nepravilnosti i nedostataka tržišta rada u kulturi i brzu intervenciju u tim oblastima. Koliko suviše afirmativna politika zapošljavanja, koja teži ka tome da obezbedi stalan posao velikom broju radnika u kulturi, može voditi ka stagnaciji cele oblasti, toliko previše restriktivne i generalizovane mere za zapošljavanje i prepuštenost slobodnom tržištu mogu povećati nezaposlenost. Činjenica je: ako se kultura finansira da bi se postigli kulturno-specifični ciljevi, šanse su dobre da će se oni i ostvariti. Naprotiv, ako se kultura finansira samo da bi se obezbedila stalna radna mesta, onda rezultati sigurno neće ispuniti očekivanja.

Dakle, po pitanju zapošljavanja u oblasti kulture teško je dati jednostavno ili jedinstveno rešenje. Ono se tiče ekonomskih, pravnih i organizacionih instrumenata kulturne politike koji se razlikuju od zemlje do zemlje, te je nemoguće predložiti jedinstvenu legislaciju na evropskom nivou. Takođe, svako rešenje ima svoje prednosti, ali i mane: ako umetnicima obezbedimo specijalne olakšice, ostatak društva može da dobije utisak da su umetnici privilegovani ili, sasvim suprotno, da su socijalno zavisna niža klasa; s druge strane, ako ne napravimo nikakvu razliku između uslova rada u oblasti kulture i u drugim oblastima, možemo da ugrozimo socijalni status velikog broja umetnika, stvaralaca, kulturnih radnika, što dalje može voditi ka devastaciji nacionalnog kulturnog potencijala. U osnovi svega jeste pitanje: da li je podrška umetnicima najbolji način da se podrži umetnost? ${ }^{24}$

Dakle, svaka zemlja bi trebalo da traga za rešenjem koje najviše odgovara specifičnostima njenog kulturnog sistema. Takođe bi bilo dobro da države razmotre međusobna iskustva i prakse koje su se pokazale dobrim, naročito

23 Pogledati uporednu tabelu u dokumentu Saveta Evrope i ERICarts Instituta, Social Security Laws and Measures to Support Self-Employed Artists, 5. april 2010, http://www.culturalpolicies.net/web/ comparisons-tables.php?aid $=34 \& \operatorname{cid}=45 \& l i d=e n$

24 Matarasso F. i Landry C., Balancing Act: 21 strategic dilemmas in cultural policy, Council of Europe 1999, str. 52. 
zbog sve veće mobilnosti umetnika i globalizacije tržišta. Upoznavanje sa načinom rešavanja pravnih i profesionalnih problema umetnika u drugim zemljama Evropske unije može dovesti do inovativnih rešenja, prilagođenih potrebama i vrednostima sopstvenog sistema.

Druga preporuka koja se odnosi na sve četiri zemlje jeste sprovođenje neophodnih akcija kojima bi se edukacija mladih profesionalaca uskladila sa specifičnim potrebama tržišta u kulturi i kako bi se popravile njihove šanse za zapošljavanje. Jedna takva akcija bi moglo biti usklađivanje univerzitetskih programa i izdavanje međunarodno priznatih kvalifikacija, čime bi mladi kadrovi u kulturi postali konkurentni na global(izova)nom tržištu. ${ }^{25}$ Jasno je da ovakva akcija zahteva blisku međuresornu saradnju između ministarstava kulture, obrazovanja, rada itd. svake zemlje.

Treća preporuka se odnosi na pronalaženje takvih sistemskih rešenja kojim bi informacije o ponudama na tržištu rada za kadrove u kulturi postale jasne i dostupne. To može biti postignuto razvijanjem mreže umetničkih agenata, umetničkih sindikata (eng. trade unions), otvaranjem posebnih portala za sve aktere u oblasti kulture, itd. Bez obzira na model kulturne politike određene države, informisanost radne snage i poslodavaca o međusobnim potrebama i očekivanjima je osnovni preduslov za unapređenje politike zapošljavanja u kulturi.

Pored ovih, za svaku zemlju je moguće dati nekoliko posebnih preporuka, ali kako je cilj ovog rada da analizom primera dobre prakse predloži najefikasnije načine za rešavanje politike zapošljavanja u oblasti kulture u Srbiji, fokusiraćemo se na ona strateška rešenja i instrumente koji mogu biti implementirani u Srbiji.

Prva preporuka za dugoročno unapređenje politike zapošljavanja u oblasti kulture u Srbiji bila bi da se, po ugledu na britanske, razvije sistem dodele dotacija, programa profesionalnog usavršavanja i razvoja preduzetništva, $\mathrm{s}$ obzirom da oni doprinose kako porastu zaposlenosti tako i promovisanju izvrsnosti. Posebnu pažnju u okviru ovih programa bi trebalo posvetiti treninzima i kursevima o fundraising-u, menadžmentu i marketingu u kulturi, kako bi se, dugoročno gledano, srpski kulturni poslenici opskrbili neophodnim veštinama za opstanak na slobodnom tržištu. Kao što smo videli, zbog precizno definisanih ciljeva kulturne politike i njihove dosledne implementacije, Britanija je razvila izuzetno preduzetnički orijentisan kulturni sektor, koji se lako nosi sa silama slobodnog tržišta. Mnogi stimulativni ekonomski instrumenti su razvi-

25 Mundy S., Cultural Policy: A Short Guide, Council of Europe 2000, str. 91 . 
jeni kako bi se pomoglo radnicima u kulturi da opstanu na tržištu rada. Iako se uvođenje naknade za traženje posla po ugledu na britanski model za sada ne čini primenjivim u Srbiji, dugoročna politika zapošljavanja bi takođe trebalo da ima u vidu da je samozaposlene umetnike i radnike u kulturi neophodno zaštititi određenim ekonomskim i socijalnim merama, naročito ako se teži ka promeni načina zapošljavanja u javnom sektoru (prelazak sa stalnog na zapošljavanje na određeno vreme, tj. po ugovoru/projektu).

U istom cilju, Srbija bi mogla da se posluži primerima dobre prakse iz Finske, koja je već razvila velik broj indirektnih i direktnih mera kojima se podstiče profesionalna angažovanost radnika u kulturi. Važnu ulogu u ovome igra razgranat sistem umetničkih saveta Finske, te dobra saradnja i podela odgovornosti između državnih i lokalnih vlasti. Iako geopolitički sistem Srbije ne funkcioniše po arm's lenght ${ }^{26}$ principu, strategija decentralizacije na kojoj se sve više insistira bi dugoročno gledano mogla veoma povoljno da se odrazi i na politiku zapošljavanja u kulturi. U tom pogledu, decentralizacija bi mogla da obuhvati otvaranje mogućnosti za razvoj lokalnih strategija za zapošljavanje u kulturi (u okviru nacionalne), kao i podsticanje veće mobilnosti umetnika, te promociju stvaralaštva van prestonice i većih gradova Srbije.

Međutim, u obe gore pomenute zemlje nedostaje razumevanje od strane nosilaca vlasti za specifičnosti pojedinih profesija u oblasti kulture. Kako bi se dosadašnji proaktivni pristup Finske i dalje nastavio, neophodno je da se finsko Ministarstvo kulture i obrazovanja izbori za uključenje i uvažavanje specifičnosti tržišta rada u kulturi u okviru nacionalne strategije za zapošljavanje. Ova preporuka se takođe odnosi i na Srbiju, jer bi se time postigao još bolji uvid od strane državnih vlasti u problematiku zapošljavanja u kulturi, a samim tim i razvoj strateških planova koji su usklađeni sa potrebama radnika u kulturi. Kako je u Finskoj kao i u Srbiji preduzetnički sektor u kulturi slabo razvijen, Ministarstvo ekonomije obe zemlje bi moglo da ponudi preduzetnicima specijalne uslove za osnivanje malih preduzeća u kulturnim i kreativnim industrijama. To bi mogle biti, na primer, povoljnije kamate na kredite. Ovakvom merom bi se istovremeno podstaklo širenje efikasnog, preduzetničkog sektora u kulturi, ali i poboljšale razvojne mogućnosti najperspektivnije industrije u Evropi.

26 eng. na dužinu ruke, termin koji označava princip delegirane odgovornosti, kakav je, na primer, zastupljen u Velikoj Britaniji i u Finskoj, prema kojem se alokacija vladinih fondova za kulturu vrši pomoću sistema nezavisnih umetničkih saveta. 
Kulturna politika Srbije i, u okviru nje, politika zapošljavanja, trenutno pokazuju najviše sličnosti sa kulturnom politikom Rusije (u odnosu na preostale dve analizirane zemlje). Kao i Rusija, na svom putu ka modernoj, demokratskoj državi, Srbija ima da razreši još mnoga pitanja, kao što je decentralizacija i delegiranje moći regionalnim i opštinskim vlastima, podrška razvoju samoodrživog resora, smanjenje uloge „države-mecene“, stvaranje ekonomskih i pravnih podsticaja za poslovne investicije i razvoj privatnog sektora u kulturi, itd. Tek nakon što pravne osnove savremene kulturne politike budu postavljene, mere po pitanju zapošljavanja u oblasti kulture mogu biti razmotrene.

Naravno, kako bi do ikakvih promena došlo, neophodno je da se promeni filozofija političkih struktura, to jest da donosioci odluka obe zemlje, u skladu sa svetskim trendovima, počnu da gledaju na kulturu kao razvojno-ekonomski potencijal, a ne samo kao nezaobilazni javni trošak. U okviru strategija regionalnog razvoja, na primer, regionalne vlasti bi mogle da razviju specijalne programe kojima se privlače mladi preduzetnici u kulturi u ruralna područja. Time bi se postigli ravnomerniji efekti politike zapošljavanja u svim regijama, ali i bolja distribucija i decentralizacija kulturne produkcije. U cilju poboljšanja produkcije, takođe je potrebno da se uspostavi sistem dotacija i fondova kojima se podržavaju kreativni procesi, a ne samo rezultati/prezentacija.

Osim ovih, dugoročnih mera, preporučenih na osnovu primera dobre prakse drugih zemalja i podudarnosti određenih problema, moguće je predložiti i nekoliko kratkoročnih mera kojim bi se rešili trenutni problemi zapošljavanja u oblasti kulture u Srbiji. Važno je ipak reći da je, nakon dekade potpune devastacije svih kulturnih vrednosti (tokom devedesetih), kulturna politika Srbije počela da se okreće ka filozofiji slobodnog tržišta. Međutim, problem je u tome što se tržištu priznaje visoka vrednost, a da ono zapravo još uvek ne postoji. ${ }^{27}$ Promene koje su se desile tokom prethodnih nekoliko godina, kao i one koje će se dogoditi ukoliko novi Zakon o kulturi zaživi, mogu biti pozitivno ocenjene. Ipak, još uvek nedostaje mnogo podzakonskih akata i mera kojim bi se zaštitila prava na zapošljavanje radnika u kulturi.

Pre svega, neophodno je da ustanove kulture podstaknu dalju profesionalizaciju i usavršavanje umetnika, naročito onih koji nisu navikli na uslove rada na slobodnom tržištu. To može biti postignuto kreiranjem različitih tre- 
ninga i life-long learning programa ${ }^{28}$ prema svetskim umetničkim trendovima i prema potrebama samih institucija. Sistemom nagrada i vrednovanja profesionalnog napretka/angažmana, još više bi se doprinelo ovom cilju.

Potom, potrebno je da se broj školovanih mladih umetnika/profesionalaca koji se pojavljuju na tržištu kulture usaglasi sa potrebama tržišta rada, što zahteva veliku koordinaciju ministarstava kulture, rada i obrazovanja, a koja hronično već godinama izostaje. Time bi se izbeglo prezasićenje tržišta i pojava velikog broja nezaposlenih kadrova. Takođe je neophodno da se čitava oblast kulture (re)organizuje, na primer, osnivanjem agencija koje bi pratile razvoj oblasti $\mathrm{i}$ informisale kadrove u kulturi oko njihovih profesionalnih prava i mogućnosti.

Kriterijumi za isplatu doprinosa socijalnog osiguranja još uvek treba da se usklade sa uslovima rada slobodnih i samozaposlenih umetnika. Zadatak je Ministarstva kulture da kreiranjem posebnih podzakonskih akata u okviru važećeg Zakona o kulturi ponudi najbolje rešenje za ovo pitanje i da lobira za njegovo usvajanje od strane republičke skupštine. Takođe je neophodno da organi državne uprave sprovedu oštriju kontrolu da li opštine redovno plaćaju socijalno osiguranje za slobodne umetnike.

Poslednja preporuka se odnosi na uspostavljanje različitih podsticajnih mera (poreskih olakšica, mikrokredita i slično) za razvoj kreativnih industrija i kulturnog turizma, kao indirektnog načina da se podstakne zapošljavanje. Ministarstvo kulture treba da, u saradnji sa Ministarstvom ekonomije, prepozna potencijale za razvoj kreativnih industrija i kulturnog turizma u Srbiji, te da na osnovu analize raspoloživih resursa, izabere najpodsticajnije mere. „Odluka o najboljem rešenju treba da bude doneta na osnovu procene (evaluacije) raspoloživih rešenja, pri čemu su kriterijumi procene: delotvornost (efektivnost), efikasnost, pravednost, izvodljivost (sprovodljivost) i fleksibilnost." ${ }^{29}$ Ukoliko Ministarstvo još uvek nije spremno na ovakav korak, opštine i gradovi bi mogli preuzeti inicijativu za razvoj istih na lokalnom nivou. Besplatno korišćenje objekata u vlasništvu grada (u prvih godinu dana rada, dok se ne povrati uloženi kapital) i nabavka kancelarijske opreme, na primer, su samo neke od mera koje grad može ponuditi mladim preduzetnicima u kulturi.

28 Program doživotnog učenja, kontinuiranog profesionalnog usavršavanja.

29 Đukić V., Država i kultura, Institut za film, pozorište, radio i televiziju, Fakultet dramskih umetnosti Beograd 2010, str. 414. 


\section{LITERATURA:}

Davies R. i Lindley R., Artists in figures: A statistical portrait of cultural occupations, Arts Council England 2003, str. XIII

Dragičević Šešić M., Cultural Policies and Cultural Management Reader, Budapest 1999, str. 27.

Dragičević Šešić M., Cultural Policy in Serbia: National Report. Council of Europe 2003.

Dufton B., Cultural Policy in Serbia and Montenegro: Part I:

Republic of Serbia Experts' Report. Council of Europe 2003, str. 31.

Đukić V., Država i kultura, Institut za film, pozorište, radio i televiziju, Fakultet dramskih umetnosti Beograd 2010

ERICarts Institute, The Status of Artists in Europe, European Parliament 2006.

Matarasso F. i Landry C., Balancing Act: 21 strategic dilemmas in cultural policy, Council of Europe 1999, str. 52.

Mundy S., Cultural Policy: A Short Guide, Council of Europe 2000, str. 91.

UNESCO Recommendation concerning the Status of the Artists, Belgrade 1980

Zakon o državnoj upravi, Službeni glasnik R. Srbije, br. 79/2005 i 101/2007.

Zakon o kulturi, Službeni glasnik R. Srbije, br. 72/2009.

Zakon o radu, Službeni glasnik R. Srbije, br. 24/ 05 i 61/05.

Zakon o udruženjima, Službeni glasnik R. Srbije, br. 51/2009.

\section{WEBOGRAFIJA:}

Creative Industries, 5. april 2010., http://www.culture.gov.uk/ what_we_do/Creative_industries/

Finland Cultural Policy Profile, Compendium: Cultural Policies and Trends in Europe, 30. novembar 2008., 05. januar 2010.,

http://www.culturalpolicies.net/web/finland.php?aid=33

Russia Cultural Policy Profile, Compendium: Cultural Policies and Trends in Europe, 01. septembar 2009, 05. januar 2010, http://www.culturalpolicies.net/web/russia.php

Serbia Cultural Policy Profile, Compendium: Cultural Policies and Trends in Europe, 29. novembar 2009., 5. januar 2010., http://www.culturalpolicies.net/web/serbia.php

Social Security Laws and Measures to Support Self-Employed Artists, 5. april 2010, http://www.culturalpolicies.net/web/ comparisons-tables.php?aid $=34 \&$ cid $=45 \&$ lid $=$ en

Standard Occupational Classification 2000, 5. januar 2010, http://www.statistics.gov.uk/methods_quality/ns.../SOC2000. doc

United Kingdom Cultural Policy Profile, Compendium: Cultural Policies and Trends in Europe, 28. novembar 2008, 05. januar 2010, http://www.culturalpolicies.net/web/unitedkingdom.php?aid=1

What is Equity, 5. april 2010., http://www.equity.org.uk/AboutUs/WhatIsEquity.aspx 
SLAVICA VUČETIĆ

\author{
Slavica Vučetić \\ Beograd University of Art, UNESCO Department of Cultural Policy \\ and Management

\section{EMPLOYMENT POLICIES FOR THE CULTURAL} \\ SECTOR
}

\begin{abstract}
Employment policies for the cultural sector are, naturally, the intrinsic part of the status of the artists. They can be both restrictive and stimulating instruments for cultural bloom of any country. Employment policies require good integration of several policy areas, namely economics, social affairs, health and labor. That makes them an extremely complex and interesting issue for discussion. During the 21th general conference of UNESCO in Belgrade (1980), a list of Recommendations concerning the Status of the Artist was set up, which stressed that ,(artists') conditions of work and of employment should be such as to provide opportunities for artists who so wish to devote themselves fully to their artistic activities." However, in practice, different countries have taken with different seriousness all the measures proposed, which has resulted in numerous and qualitatively different methods of regulation of the artists' status. The aim of this paper is to show how too affirmative employment policy which aims at providing secure jobs for an array of employees can lead toward stagnation of the whole sector, as well as how too restrictive and generalized employment measures and abandonment to free market forces can increase unemployment. Comparing the employment policies for the cultural sector of two EU and two non-EU countries, this paper discusses advantages and disadvantages of all four policy models and designs a cultural policy proposal for each of them. The research carried out in January 2010 showed that the UK and Finland have more developed employment policies and more entrepreneurial cultural workforce than Serbia and Russia, which still struggle with transitional circumstances. However, each state lacks consideration for the specific work conditions of certain artistic occupations, primarily the status of self-employed artists. Policy proposals are, thus, created according to the specific needs of their cultural sectors and examples of good practices of other European countries.
\end{abstract}

Key words: employment, status of artist, freelance artists, social protection 